\title{
Experimental observations and micromechanical modeling of successive-damaging phenomenon in wood cells' tensile behavior
}

\author{
Marjan Sedighi-Gilani · Parviz Navi
}

Received: 29 December 2005/ Published online: 12 July 2006

C) Springer-Verlag 2006

\begin{abstract}
Single wood cells have complex tensile behavior. To gain insight into this complex functionality, the behavior of single wood tracheids was studied under controlled cyclic tensile loading. The cyclic tensile stress-strain curves show that beyond the yield point the tracheid undergoes permanent deformations and its rigidity increases. As in plasticity elastic (or visco-elastic) unloading takes place and energy is dissipated by permanent deformation. Consequently, single tracheids show a load-history dependent behavior. To understand the intervening mechanism in the process of elasto-plastic response of a wood tracheid, a micromechanical based model was developed. This model permits us to describe the influence of non-uniformity of microfibril angle (MFA) and other defects on the wood cell rigidity and to discuss different scenarios, which may occur during the tensile test. Successive damage of the hemicelluloses and lignin matrix and reduction of MFA as mainly responsible for elasto-plastic response of a wood cell were suggested. It should be noted that this paper is part of the research work which has been reported previously (Navi et al. in Wood Sci Technol 29:411-429, 1995; 36:447-462, 2002; Sedighi-Gilani et al. in Wood Sci Technol 39:419-430, 2005).
\end{abstract}

\section{Introduction}

There are numerous experimental studies investigating the behavior of single wood cells in tension (Page and El-Hosseiny 1983; Groom et al. 2002b; Groom et al. 2002a; Burgert et al. 2002). All these experiments have shown that the

\footnotetext{
M. Sedighi-Gilani $\cdot$ P. Navi $(\bowtie)$

Institute of Materials Science, Ecole Polytechnique Fédérale de Lausanne,

1015 Lausanne, Switzerland

e-mail: Parviz.Navi@epfl.ch
} 
tensile behavior of single wood cells is complex and cannot be described by the simple linear elasticity. On the other hand, estimation of the elastic properties of cell wall has been the subject of several approaches. Mark (1967) reviewed the early literature on cell wall models and proposed a model of single tracheid to compute the internal stresses. Following this work, many researchers (Cave 1968, 1969; Schniewind and Barrett 1969; Salmmén and de Ruvo 1985) developed two-dimensional models based on micromechanical approaches and predicted the longitudinal elastic modulus of a single wood cell as a function of mean microfibril angle (MFA). Later, Navi (1988), Harrington (2002), and Persson (2000) estimated the elastic rigidity of wood cells by using three-dimensional models. Wood multi-scale modeling (Perré 2001) and more advanced micromechanical modeling of the wood cell wall (Bergander and Salmén 2002) were the other important achievements in this field. In spite of these important findings, the models could only predict the behavior of single tracheids in the elastic zone and no model existed to explain the complex stress-strain behavior of single wood tracheids after the yield point.

Evidences of experimental results showing the elasto-viscoplastic behavior of thin wood tissue under controlled cyclic tensile loading are remarkable (Navi et al. 1995; Keckes et al. 2003). Navi et al. (1995) showed that the loadextension curves of thin wood specimens consist of three distinct segments. The first segment is almost a straight line. At some level of loading, a yield point is observed and beyond this point the specimen undergoes large permanent deformations. In this segment, the specimen macroscopically behaves like an elasto-plastic material with positive hardening. However, the rigidity of the specimen after the yield point does not decrease and as the load is further increased, the slope of the curve increases significantly (third segment) with no evidence of yielding occurring in the specimen. Based on these experimental results, a micromechanical model was built to explain the elastoplastic behavior of thin wood tissue by occurrence of matrix degradation (yielding) and local decrease of MFA. In this model, two important hypotheses were made; first considering the MFA non-uniform along one wood tracheid and second the possibility of local degradation of the matrix (lignin and hemicelluloses). However, each of these hypotheses had to be validated either by experimentations or by modeling. On one hand, recent observations of the local MFA in single wood tracheids using different techniques such as soft-rot cavity (Anagnost et al. 2002; Khalili et al. 2001), improved iodine method (Wang et al. 2001) and confocal laser scanning microscopy (SedighiGilani et al. 2005, 2006) showed that, contrary to what was assumed before, microfibril orientation in one wood tracheid is non-uniform. On the other hand, the possibility of local degradation of the cell wall matrix was reinforced by recent models (Navi et al. 2002; Navi and Sedighi-Gilani 2004).

The main objective of this work was to investigate the underlying mechanisms in the complex behavior of single wood tracheids. It is explained that in spite of the possibility of occurrence of slip mechanisms at molecular level which was explained in Navi et al. (2002) and Keckes et al. (2003) other 
phenomena like local reduction of MFA and successive damaging of the matrix are responsible for the complex behavior of wood tracheids.

\section{Materials and methods}

\section{Tracheid preparation}

Small cubic pieces of juvenile wood, mature wood and compression wood (spruce) were cut and saturated in deionized water to facilitate chipping thin layers (about $100 \mu \mathrm{m}$ ) with a microtome. Cubs were chipped in the radial direction. Both earlywood and latewood tracheids were mechanically peeled out from the wet wood chips using fine tweezers. Because of the plentiful existence of bordered pits in earlywood tracheids, their mechanical isolation was more difficult than that of latewood tracheids. Another difficulty of sample preparation was the tendency of the single tracheids to twist after isolation and drying. It was shown that hygroexpansion during humidity changes in an orthotropic lamina caused the shear stresses in the fiber wall and led to twisting of the fiber (Studer 2005). The tendency to twist in the mechanically isolated tracheids, though smaller than the chemically macerated tracheids, is still present. The results of tensile tests on twisted fibers can be different to the results of non-twisted fibers due to stress concentration in the twisted zones and their obtained stress-strain curves do not show the overall behavior of the intact wood fibers. Therefore, controlling the single isolated tracheids under the microscope and removing the tracheids which were twisted during preparation is important. The method developed by Kersavage (1973), placing the epoxy droplets on the ends of tracheid, was used to grip the tracheids in the mini-press (see Fig. 1). Mechanical isolation of the

Fig. 1 A prepared tracheid for tensile test

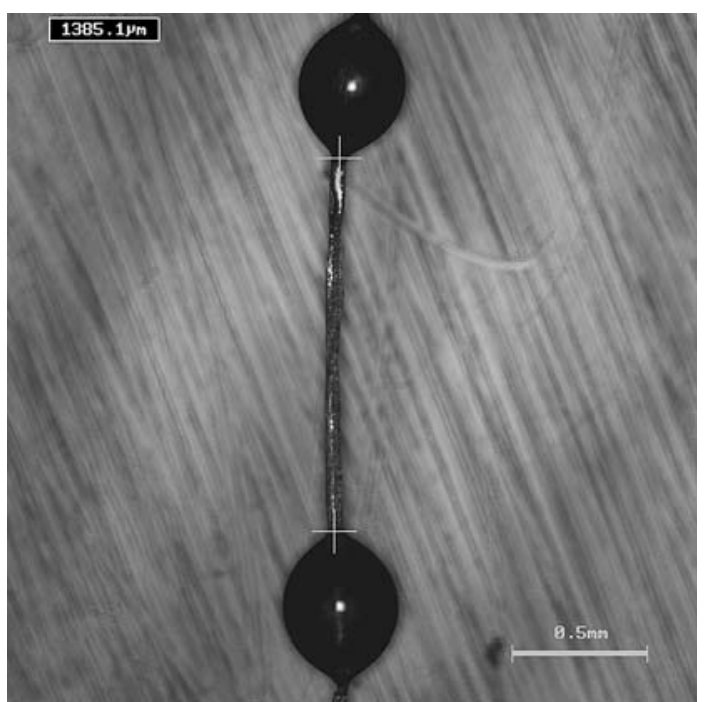


tracheids and preparation of the samples were performed at room temperature and humidity and during microscopic observation.

Tensile testing mini-press

To perform the tensile tests on single wood tracheids, a displacement controlled mini-press was developed. The mini-press system records the amount of generated forces when the known displacement is applied by twisting the displacement screw.

The portability and small size of the device helps us to perform the in-situ tensile tests during microscopic observation. In Fig. 2, the machine installed on the microscope stage is shown.

Two semi-circular steel pieces with conical holes were mounted at the ends of the displacement beams to grip the sample. The prepared sample with two spherical shaped epoxy droplets at the ends are placed in these holes and are gripped between them in tension. In Fig. 3a, one of these semi-circular steel pieces is shown.

Because of the small size of the specimens, placing a specimen between the machine clamps along its longitudinal axis when properly aligned with the force direction is difficult. To ease the placement of the specimen between the machine clamps in a correct alignment, a device called micro-band which aligns the longitudinal axis of tracheid with the force axis, was developed and installed on the mini-press system (Perez et al. 2000). As Fig. 3b shows, the micro-band has two vertical and horizontal adjusting screws which can vertically and horizontally move one end of the tracheid and align its longitudinal axis in the force direction.

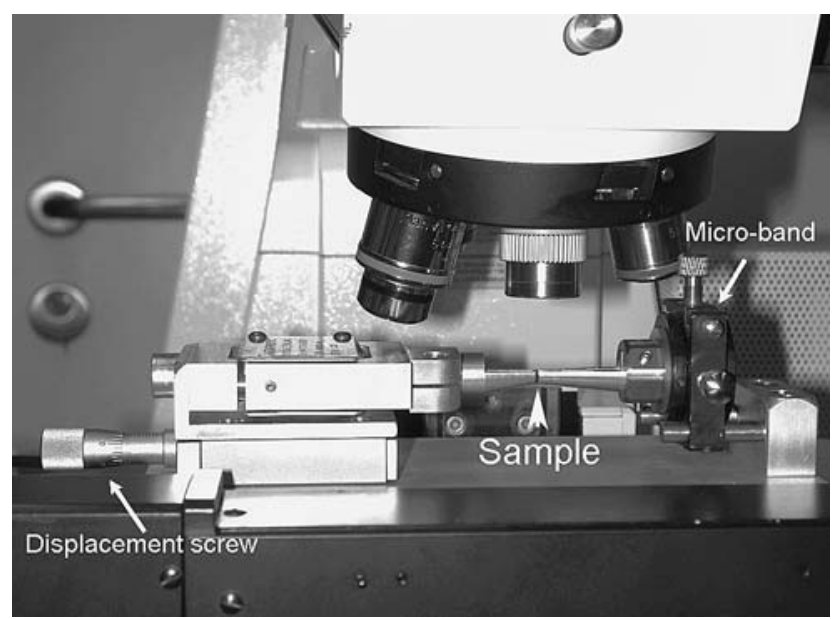

Fig. 2 Tensile testing mini-press installed on the confocal microscope stage, displacement screw, micro-band and the sample gripping position are marked with white arrows 

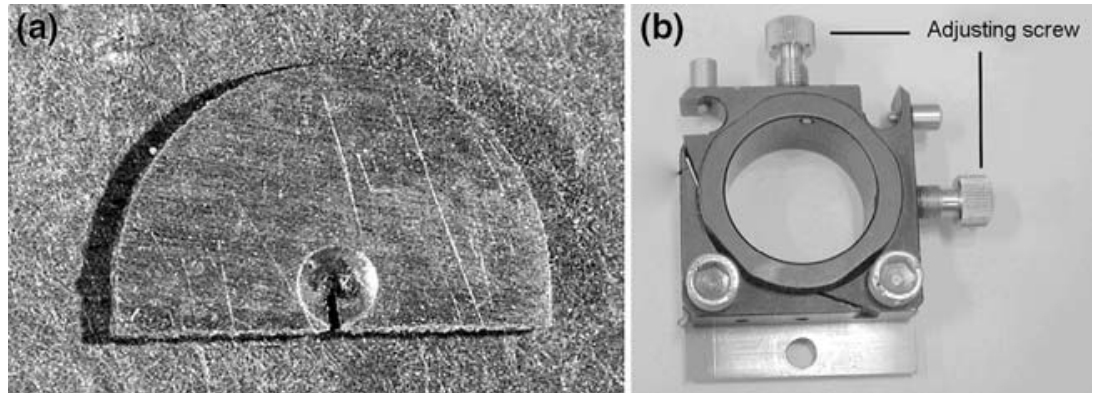

Fig. 3 Tensile testing mini-press attachments. a Semi-circular steel piece with conical holes working as the clamps, $\mathbf{b}$ micro-band with two screws for adjusting the tracheid alignment

\section{MFA measurement}

A Carl Zeiss LSM 310 Confocal laser scanning microscope (CLSM), equipped with an argon laser (excitation at $488 \mathrm{~nm}$ ) and a rotating half-wave plate, was used to measure the local MFAs of isolated wood tracheids and other features such as cross-sectional area and length. CLSM allows us to measure the local MFAs of $S_{2}$ layer - the tracheid's thickest wall layer - without degrading the main structure of the cell wall. These results (Sedighi-Gilani et al. 2005) show that MFAs are highly variable within the radial wall of earlywood tracheids, especially in the vicinity of the bordered pits. MFA in latewood fibers and tangential wall of earlywood fibers, though less than earlywood fibers, was still non-uniform.

\section{Results and discussion}

\section{Tensile test analyses}

Two series of experiments, simple tensile tests and cyclic tensile tests were carried out. The cyclic tensile tests were performed to elucidate the plasticity response of single tracheids under simple tension.

For each applied displacement, the mini-press permits to measure the corresponding force. The obtained force-displacement curve is converted to the stress-strain curve by measuring the effective length and cross-sectional area of the tracheid before testing. Effective length being the length of the tracheid between the epoxy droplets is measured with the microscope. The cross-sectional area of the cell is measured by scanning through the depth of the cell by argon laser (488 nm wavelength) with confocal laser scanning microscope. One should note that the tracheids' natural defects have important influences on their tensile behavior and in tracheids having defects such as cross-field and bordered pit zones, tracheid failure often occurred close to these areas. 


\section{Stress-strain curve of single tracheid under tension}

Experiments show that the stress-strain curves of single wood tracheids are usually different in various tracheids. Compression wood tracheids have apparently lower stiffness and higher strain potential than normal wood tracheids. In Fig. 4, the tensile behavior of two spruce earlywood tracheids taken from normal and compression parts of the stem are shown. The compression wood tracheid was tested under wet conditions because humidity increases the strain potential in the cells.

In this figure, the stress-strain curve of compression wood tracheid has three distinct segments. The slope of the first segment of stress-strain curves shows the effective Young's modulus of the tracheid. After the yield point, the slope of the stress-strain curve decreases but remains positive in the second part and increases again in the third segment.

In Fig. 5, the response of more individual spruce tracheids under axial tension is shown while the local MFAs at different points along each tracheid were measured prior to experiments. Because MFA measurement using CLSM techniques needs manipulations and contains the risk of harming the tracheids before testing, the measurement of no more than three or four points along each tracheid was undertaken. Consequently, there is little information concerning the exact morphology of cellulose microfibrils in the other parts. However, this example reconfirms that local MFAs are variable in different parts of a single tracheid and the tensile behavior of a wood tracheid is not a simple function of the mean MFA.

The slope of the stress-strain curves and the strength of the tracheids were affected by the range of existing natural defects and non-uniformities of the MFA.

Stress-strain curve of a single tracheid under cyclic tension

Cyclic tensile tests provide more information about the tensile behavior of wood tracheids. In Fig. 6, the behavior of two compression wood tracheids under cyclic tensile testing is shown.

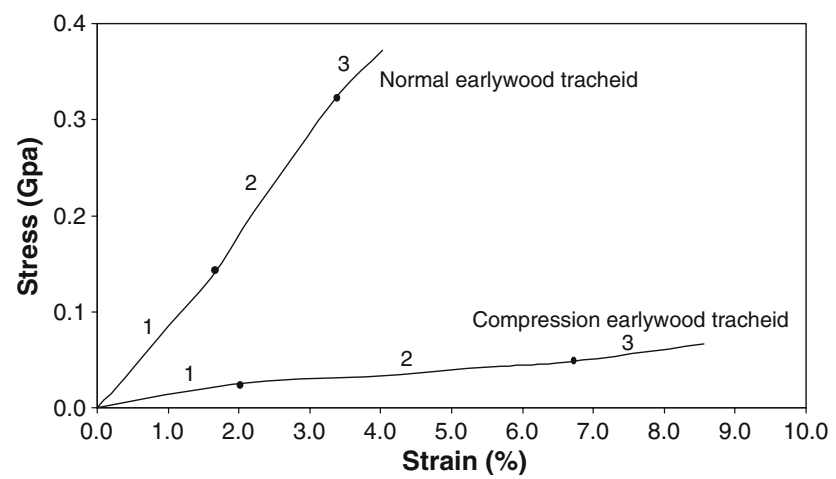

Fig. 4 Stress-strain curves of single spruce tracheid under tension, an earlywood tracheid tested under dry condition and a compression earlywood tracheid tested under wet condition 


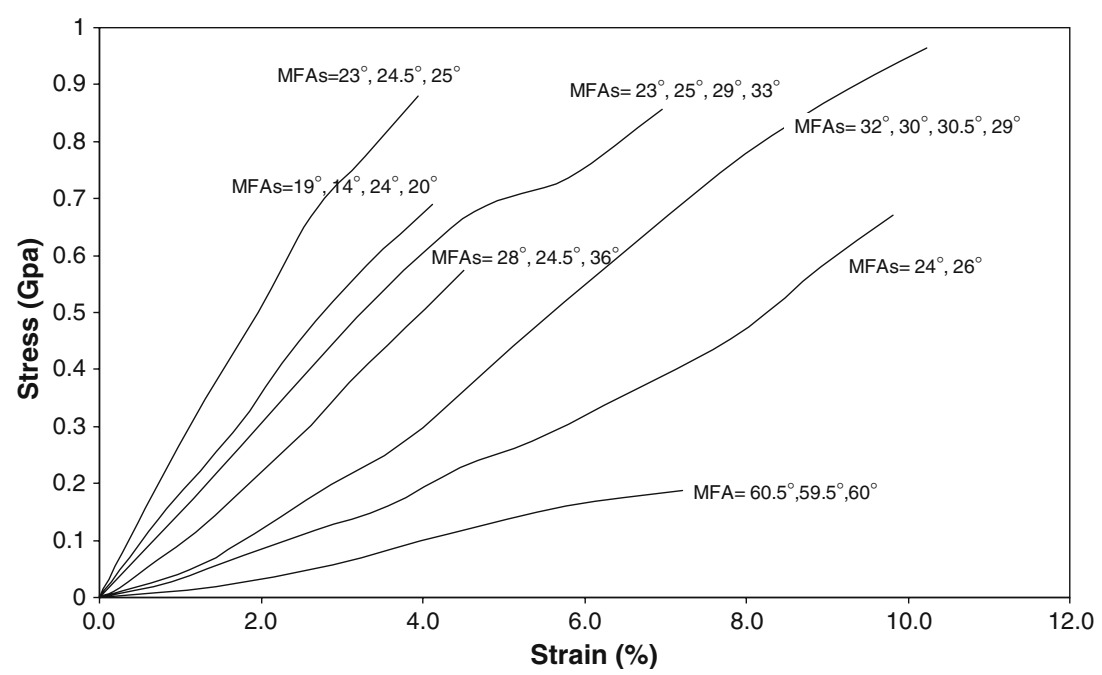

Fig. 5 Stress-strain curves of dry wood tracheids under tensile test, measured local MFAs at some points along tracheid are mentioned

The slope of the first segment in both curves shows the effective modulus of elasticity of the intact tracheid. At some stage of loading (point 1, between a and b) a yield point is observed. Beyond this point, the tracheid undergoes a large, mainly irreversible deformation, and the slope of the stress-strain curve (line through 1 and 2) decreases but remains positive. The positive slope of the stress-strain curve after the yield point indicates no strain softening phenomenon. During loading the stiffness of the tracheid increases (increasing slope of the loading-unloading cycles, lines cd, ef, gh, ij and $c^{\prime} d^{\prime}$ and $\left.e^{\prime} f^{\prime}\right)$. These phenomena are attributed to the microstructural evolutions in the cell wall and are responsible for the third segment of stress-strain curve; segment with a higher slope after point 2.

Here, a summary of the important observations in the cyclic tensile test is presented:
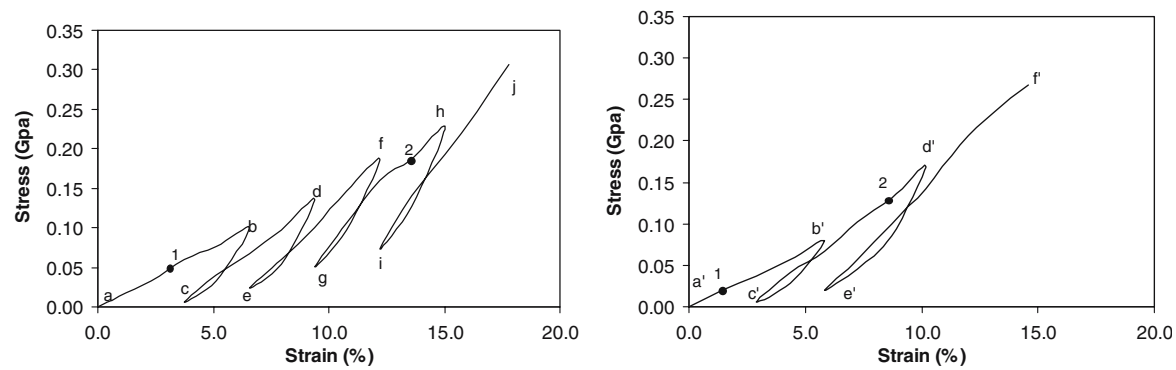

Fig. 6 Stress-strain curve of compression wood tracheids under loading-unloading tensile test. a Tracheid tested under wet condition, MFA was $37^{\circ}$, $\mathbf{b}$ tracheid tested under wet condition, MFA was $32^{\circ}$ 
1. Residual strains after each cycle.

2. Force-history dependent behavior (Navi et al. 1995).

3. Increase of the Young's modulus during loading.

These phenomena could be the consequence of the successive damage and microfibrillar evolutions in the cell wall which will be discussed by way of the following model.

Modeling the tensile behavior of single wood tracheids

Unable to visualize the evolution of wood cell ultrastructure under tension, a micromechanical model was developed. This model describes the tensile behavior of wood tracheids in relation to their microstructure and possible structural evolution and damage. Main assumptions of the model are:

1. Wood cells are long hollow cylinders of length $L$. For simplicity, the cell wall is made of the $S_{2}$ layer only and is composed of lignin and hemicellulose matrix reinforced by helical cellulose microfibrils.

2. All natural defects like cross-field zones, dislocations, micro compressions, and slip planes which affect the local orientation of microfibrils along the tracheid, are replaced by MFA non-uniformities. In this way a set $\left(\alpha_{1}\right.$, $\left.\alpha_{2}, \ldots, \alpha_{n}\right)$ is considered to represent the local MFAs of different segments of a wood tracheid such that:

$$
\alpha_{1}>\alpha_{2}>\cdots>\alpha_{n}
$$

3. Each $\alpha_{i}$ is assumed to be constant along the segment length, $L_{i}$ belonging to the set $\left(L_{1}, L_{2}, \ldots, L_{\mathrm{n}}\right)$ such that:

$$
L_{1}+L_{2}+\cdots+L_{n}=L \text {. }
$$

\section{Calculation of the effective Young's modulus of a tracheid before yielding}

To obtain the effective Young's modulus of a wood tracheid with the assumed non-uniform MFAs, first the Young's modulus of segment with uniform MFA was calculated. Young's modulus of the wood fiber wall $\mathrm{S}_{2}$ layer can be calculated by using the laminate theory equations derived by Cho et al. (1972), presupposing that the geometrical and mechanical properties of the wall constituents are known:

$$
C_{i j}=\sum_{k=1}^{n} V^{k}\left[C_{i j}^{k}-\frac{C_{i 3}^{k} C_{3 j}^{k}}{C_{33}^{k}}+\frac{C_{i 3}^{k} \sum_{l=1}^{n} \frac{V^{l} C_{3 j}^{l}}{C_{33}^{l}}}{C_{33}^{k} \sum_{l=1}^{n} \frac{V^{l}}{C_{33}^{l}}}\right],(i, j=1,2,3,6),
$$




$$
\begin{gathered}
C_{i j}=C_{j i}=0(i=1,2,3,6 ; j=4,5), \\
C_{i j}=\frac{\sum_{k=1}^{n} \frac{V^{k}}{\Delta_{k}^{\prime}} C_{i j}^{k}}{\sum_{k=1}^{n} \sum_{l=1}^{n} \frac{V^{k} V^{l}}{\Delta_{k}^{\prime} \Delta_{l}^{\prime}}\left(C_{44}^{k} C_{55}^{l}-C_{45}^{k} C_{54}^{l}\right)}(i, j=4,5), \\
\Delta_{k}^{\prime}=\left|\begin{array}{ll}
C_{44}^{k} & C_{45}^{k} \\
C_{54}^{k} & C_{55}^{k}
\end{array}\right|,
\end{gathered}
$$

where $\left\lfloor C_{\mathrm{ij}}\right\rfloor$ is the stiffness matrix of the cell wall in Voigt representation $(i, j=1, \ldots, 6)$ and $C_{i j}^{k}$ is the stiffness matrix of the wood constituents corresponding to cellulose, hemicellulose and lignin for $k=1,2,3$, respectively, and $V^{k}$ is the volume fraction of the constituents.

These data were collected from existing literature in the field and summarize the three sets of low, medium and high stiffness (Persson 2000) (Table 1). The indices 1, 2, 3 in this Table denote the three principal directions: longitudinal, radial and tangential.

To calculate the stiffness tensor of the cell wall, medium stiffness values and the constituents' volume fractions at 12\% moisture contents (Cellulose 44.5 $\%$, hemicellulose $31.6 \%$ and lignin $23.9 \%$ ) were used. The calculated stiffness matrix of the cell wall in the principal axes of the microfibrils is as follows:

$$
\left[C_{i j}\right]=\left[\begin{array}{cccccc}
73.874 & 2.744 & 2.667 & 0 & 0 & 0 \\
2.744 & 11.335 & 3.367 & 0 & 0 & 0 \\
2.667 & 3.367 & 6.894 & 0 & 0 & 0 \\
0 & 0 & 0 & 2.511 & 0 & 0 \\
0 & 0 & 0 & 0 & 2.511 & 0 \\
0 & 0 & 0 & 0 & 0 & 3.635
\end{array}\right]
$$

Table 1 Engineering constants of the wood chemical constituents

\begin{tabular}{llccc}
\hline Constituent & Coefficient & Low & Medium & High \\
\hline Cellulose & $E_{1}(\mathrm{GPa})$ & 130.0 & 150.0 & 170.0 \\
& $E_{2}(\mathrm{GPa})$ & 15.0 & 17.5 & 20.0 \\
& $G_{12}(\mathrm{GPa})$ & 3.0 & 4.5 & 6.0 \\
& $v_{21}$ & 0.01 & 0.01 & 0.01 \\
Hemicellulose & $v_{32}(\mathrm{GPa})$ & 0.50 & 0.5 & 0.5 \\
& $E_{1}(\mathrm{GPa})$ & 14.0 & 16.0 & 18.0 \\
& $E_{2}(\mathrm{GPa})$ & 3.0 & 3.5 & 4.0 \\
& $G_{12}(\mathrm{GPa})$ & 1.0 & 1.5 & 2 \\
& $v_{21}$ & 0.10 & 0.10 & 0.1 \\
Lignin & $v_{3}(\mathrm{GPa})$ & 0.40 & 0.4 & 0.4 \\
& $E$ & 2.0 & 2.75 & 3.5 \\
& $v$ & 0.33 & 0.33 & 0.33 \\
\hline
\end{tabular}


Elastic properties of the wall material are calculated by using the effective compliance matrix, $\left[S_{i j}\right]$ which is the inversion of the stiffness matrix.

$$
\left[S_{i j}\right]=\left[\begin{array}{cccccc}
1 / E_{1} & -v_{21} / E_{2} & -v_{31} / E_{3} & 0 & 0 & 0 \\
-v_{12} / E_{1} & 1 / E_{2} & -v_{32} / E_{3} & 0 & 0 & 0 \\
-v_{13} / E_{1} & -v_{23} / E_{2} & 1 / E_{3} & 0 & 0 & 0 \\
0 & 0 & 0 & 1 / G_{12} & 0 & 0 \\
0 & 0 & 0 & 0 & 1 / G_{13} & 0 \\
0 & 0 & 0 & 0 & 0 & 1 / G_{23}
\end{array}\right] .
$$

These results are compared with the obtained results by Harrington et al. (1998) and Persson (2000), shown in Table 2. This comparison shows a good agreement between the matrices and numerical calculations.

To consider the role of MFA and to obtain the effective elastic properties in the cell principal directions, $\left[C_{i j}^{\alpha}\right]$, the stiffness matrix (7) was transformed by using the following transformation matrix:

$$
\left[C_{i j}^{\alpha}\right]=\left[G^{\mathrm{T}}\right]\left[C_{i j}\right][G],
$$

where $\alpha$ is the angle between the direction of microfibrils and the cell longitudinal axis (MFA) and $[G]$ is the transformation matrix between the local and global coordinate system. Considering a porosity ratio for the cell lumen (assumed here to be 0.3), the calculated Young's modulus of wood cell with MFAs varying from $0^{\circ}$ to $50^{\circ}$ is illustrated in Fig. 7.

For the defined set of MFAs in Eq. 1, the calculated Young's modulus of different segments, $E_{1}, E_{2}, \ldots, \mathrm{E}_{n}$, is written as:

$$
E_{1}<E_{2}<\cdots<E_{n}
$$

Therefore, the effective modulus of the whole tracheid, before any damage, is calculated by

Table 2 Calculated elastic properties by matrix calculation and finite elements analyses

\begin{tabular}{llll}
\hline Coefficient & $\begin{array}{l}\text { Matrix } \\
\text { calculation }\end{array}$ & $\begin{array}{l}\text { Numerical results } \\
\text { (Persson 2000) }\end{array}$ & $\begin{array}{l}\text { Numerical results }^{\mathrm{b}} \\
\text { (Harrington et al. 1998) }^{\mathrm{a}}\end{array}$ \\
\hline$E_{1}(\mathrm{GPa})$ & 72.63 & 72.6 & 63.96 \\
$E_{2}(\mathrm{GPa})$ & 9.66 & 7.48 & 9.16 \\
$E_{3}(\mathrm{GPa})$ & 5.84 & 6.13 & 9.85 \\
$G_{21}(\mathrm{GPa})$ & 2.51 & 3.13 & 3.02 \\
$G_{31}(\mathrm{GPa})$ & 2.51 & 2.97 & 3.38 \\
$G_{23}(\mathrm{GPa})$ & 3.63 & 1.75 & 2.96 \\
$v_{21}$ & 0.02 & 0.0234 & 0.33 \\
$v_{31}$ & 0.025 & 0.0208 & 0.33 \\
$v_{32}$ & 0.29 & 0.438 & 0.39 \\
\hline
\end{tabular}

${ }^{\mathrm{a}} \mathrm{S}_{2}$ and $\mathrm{S}_{3}$ layers

${ }^{\mathrm{b}} \mathrm{S}_{2}$ layer 


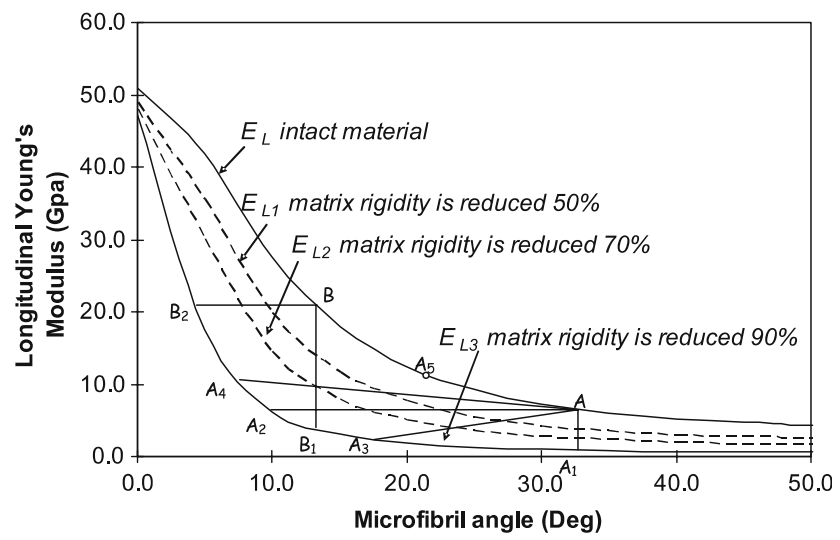

Fig. 7 Decrease of local Young's modulus in a tracheid segment corresponding to different damage states in the matrix $\left(\mathrm{EL}_{1}, \mathrm{EL}_{2}\right.$ and $\left.\mathrm{EL}_{3}\right)$ in terms of MFA

$$
\frac{1}{E_{\mathrm{eff}}}=\frac{1}{L}\left(\frac{L_{1}}{E_{1}}+\frac{L_{2}}{E_{2}}+\cdots+\frac{L_{n}}{E_{n}}\right) .
$$

\section{Calculation of tracheid Young's modulus after yield}

It was shown that in fiber composite under tension, when the fibers' rigidity is much higher than the matrix, the shear deformation of the matrix becomes dominant and leads to the matrix damage (Plummer et al. 2002). Similar to man-made composites, the cell tensile strength reduces with increase of MFA (Tsai 1988). Consequently, occurrence of damage in the wood tracheid is expected when the MFA has the highest value. Hence, beyond certain levels of tension, local matrix degradation initiates in the matrix of the weakest zone of the cell, corresponding to the highest MFA.

To calculate the effect of such degradation on the local Young's modulus and for simplification, it was assumed that the matrix damage in micro level obeys an isotropic damage and can be defined by following equation:

$$
\sigma=(1-\omega) E \varepsilon
$$

where $\omega$ is the damage parameter and $\omega=0$ indicates the intact matrix state. The damage parameter grows at various stages of the degradation and reaches $\omega=1$ corresponding to complete damage condition. In this model, reduction of the matrix elastic parameters does not affect the Poisson ratio, obeying the isotropic damage theory (Kachanov 1986).

To demonstrate the influence of matrix degradation on the local longitudinal Young's modulus of the damaged segment, the stiffness tensor should be recalculated for reduced mechanical properties of lignin and hemicellulose. 
These mechanical properties are reduced by $(1-\omega)$, for different damage parameters. The reduced properties of lignin and hemicellulose after $90 \%$ reduction are given in Table 3. As previously explained, this reduction does not follow the Poisson's ratio. In Fig. 7, the local longitudinal Young's modulus of a damaged segment, $E_{\mathrm{L} 50 \%}, E_{\mathrm{L} 70 \%}$ and $E_{\mathrm{L} 90 \%}$, corresponding to 50,70 and $90 \%$ reduction of matrix stiffness, respectively, is shown. This figure can help us to study the mechanisms underlying the tensile behavior of wood cells at the ultrastructural level. To consider the effects of local variation of MFA during local matrix degradation, different cases referring to Fig. 7 were discussed.

As a first case, we assume that after the damage initiation and during the damage process in the matrix of the weakest location of the wood cell (corresponding to highest MFA), the MFA remains unchanged. The damage in a section reduces the local Young's modulus of the tracheid (without fracture process zone) until occurrence of final failure in the cell. Indeed, the onset of damage leads to a failure of the cell. This phenomenon corresponds to lines $\mathrm{AA}_{1}$ or $\mathrm{BB}_{1}$ in Fig. 7 ( $\mathrm{A}$ and $\mathrm{B}$ are two arbitrary points on the curve). As is illustrated in Fig. 8a, the stress-strain behavior of the tracheid corresponds to an elastic behavior with brittle rupture.

However, if the MFA of the damaged zone is reduced, the local Young's modulus variation will not be the simple function of the damage parameter. Under this condition, reduction of local MFA leads to generation of irreversible strains.

Irreversible strains due to MFA reduction Cyclic tensile tests showed that beyond the yield point, the tracheid undergoes a large, mainly irreversible deformation. The total strain of the tracheid, after the yield point can be defined by

$$
\varepsilon_{\mathrm{t}}=\varepsilon_{\mathrm{e}}+\varepsilon_{\alpha},
$$

where $\epsilon_{\mathrm{e}}$ and $\epsilon_{\alpha}$ are the elastic and irreversible strains, respectively. Reduction of local MFA in a damaged zone leads to generation of irreversible strains. Figure 9 shows one segment of the modeled cell with $\mathrm{AE}=l$ as the length of

Table 3 Reduced engineering constants of the matrix after $90 \%$ damage

\begin{tabular}{lll}
\hline Constituent & Coefficient & $\begin{array}{l}\text { Property amounts after } \\
90 \% \text { reduction }\end{array}$ \\
\hline Hemicellulose & $E_{1}(\mathrm{GPa})$ & 1.6 \\
& $E_{2}(\mathrm{GPa})$ & 0.35 \\
& $G_{12}(\mathrm{GPa})$ & 0.15 \\
& $v_{21}$ & 0.1 \\
Lignin & $v_{32}$ & 0.4 \\
& $E(\mathrm{GPa})$ & 0.275 \\
& $\mathrm{~N}$ & 0.33 \\
\hline
\end{tabular}




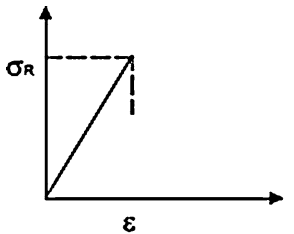

(a)

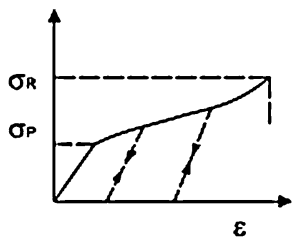

(d)

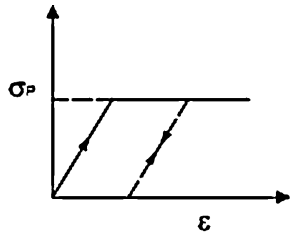

(b)

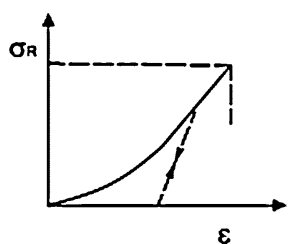

(e)

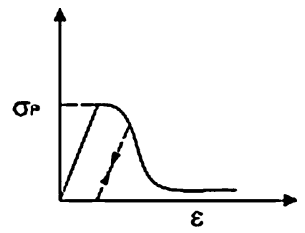

(c)

Fig. 8 Schematic representations of cell behavior undergoing different mechanisms, $\sigma_{\mathrm{R}}$ is the rupture stress and $\sigma_{\mathrm{P}}$ is the plastic limit. a Elastic behavior with brittle failure, b elasto-perfect plasticity, celasticity with ocalization and strain softening, $\mathbf{d}$ non-localized successive damage with positive strain hardening e non-localized successive sliding (MFAs are small and more uniform)

the intact segment and $\alpha$ as local MFA. If MFA reduces from $\alpha$ to $\beta$, the length of the tracheid segment elongates to $\mathrm{AB}$ and the residual strain due to MFA reduction will be:

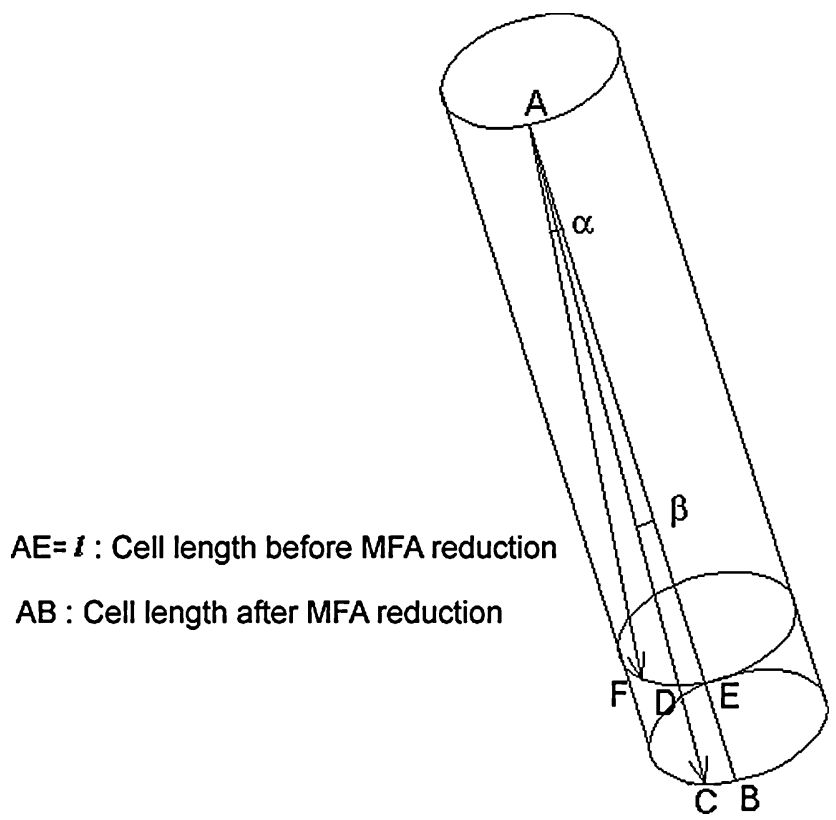

Fig. 9 Schematic representation of MFA reduction and induced deformation 


$$
\varepsilon_{\alpha}=\frac{\mathrm{BE}}{\mathrm{AE}},
$$

where $\mathrm{BE}=\mathrm{CD} \cos \beta$ and $\mathrm{CD}=\mathrm{AC}-\mathrm{AD}=\frac{l}{\cos \alpha}-\frac{l}{\cos \beta}$.

Replacing the $\mathrm{BE}$ and $\mathrm{AE}$ equivalents in Eq. 14 , the residual strain $\varepsilon_{\alpha}$ can be calculated from the following equation:

$$
\varepsilon_{\alpha}=\left(\frac{\cos \beta}{\cos \alpha}-1\right) .
$$

Depending on $\alpha, \beta$ and the length of the damaged zone, the induced strain by MFA reduction could be important, up to $50 \%$ in some cases.

If MFA of the damaged zone is reduced, the local Young's modulus variation will be the function of both damage parameter and MFA reduction and one of the following cases may occur:

- After damage initiation and during damage process, the local MFA is reduced and this reduction is such that the local Young's modulus remains unchanged (lines $\mathrm{AA}_{2}$ and $\mathrm{BB}_{2}$ in Fig. 7). In this case, a part of the total strain which is due to MFA reduction is irreversible and the behavior of the whole wood cell is analogous to the response of a perfect plastic material with large plastic deformation (Fig. 8b). This behavior could also be due to the occurrence of sliding sticking mechanism, no MFA reduction or matrix degradation (Keckes et al. 2003).

- After damage initiation, the MFA reduces while the local Young's modulus also reduces (line $\mathrm{AA}_{3}$ in Fig. 7). This case corresponds to strain softening behavior (strain localization with fracture process zone) which leads to the final failure of the wood cell (Fig. 8c).

In all the above scenarios, damage initiates in the weakest segment of the wood cell (highest MFA) and as the local stiffness in the damaged segment does not increase the final failure of the cell occurs in the same zone where the damage initiates. However, the experimentally obtained stress-strain curves of single wood tracheids are not similar to any of Figs. 8a-c. As experiments show, the tensile stress-strain curves of single wood tracheids are more analogous to an 'elasto-plastic behavior' with positive hardening (Fig. 8d, e). After the yield point no strain softening occurs and the slope of the stressstrain curve remains positive. Incidentally, the effective Young's modulus increases (increasing slope of the loading segment after unloading cycles).

Increase of the effective Young's modulus with positive hardening after the yield point can only occur if the local Young's modulus of the damaged segment increases when local MFA reduces (line $\mathrm{AA}_{4}$ in Fig. 7). Incremental damage which was initiated in the weakest segment of the tracheid allows the microfibrils to tend to straighten (local MFA reduction) and this phenomenon is accompanied by a slight increase of the local Young's modulus. When the local Young's modulus in the weakest segment increases to the modulus in the 
second-weakest segment of the tracheid $\left(E_{2}\right)$, damage initiates in this zone and also later in other parts until final failure of the tracheid. This gives the potential of large strains and non-localized multi-damaging behavior to the tracheid under tensile force. Also if the cell tensile behavior is governed by sliding and sticking in the matrix, the local Young's modulus increases while local MFA reduces, (line $\mathrm{AA}_{5}$ in Fig. 7). In this case, the effective behavior of the tracheid would be similar to Fig. 8e. Such a behavior was observed in some experimental stress-strain curves, especially in normal wood tracheids with smaller and more uniform microfibrils distribution. In Fig. 10, experimental evidence of non-localized multi-damage process of a tracheid under tensile force is shown. In Fig. 10a, a single spruce tracheid was loaded under tension and an early opening initiated at point $A$. The initiated crack grew upon increasing the applied displacement (Fig. 10b-e). However, the tracheid final failure occurred at point B (Fig. 10f). This phenomenon confirms the possibility of the last scenario, i.e., microstructural evolution of wood tracheids in tension.

The microscopic observations of non-localized damage in Fig. 10, elastoplastic macroscopic behavior with positive strain hardening in many of the wood tracheids and the tracheid's potential of straining more than $20 \%$ in
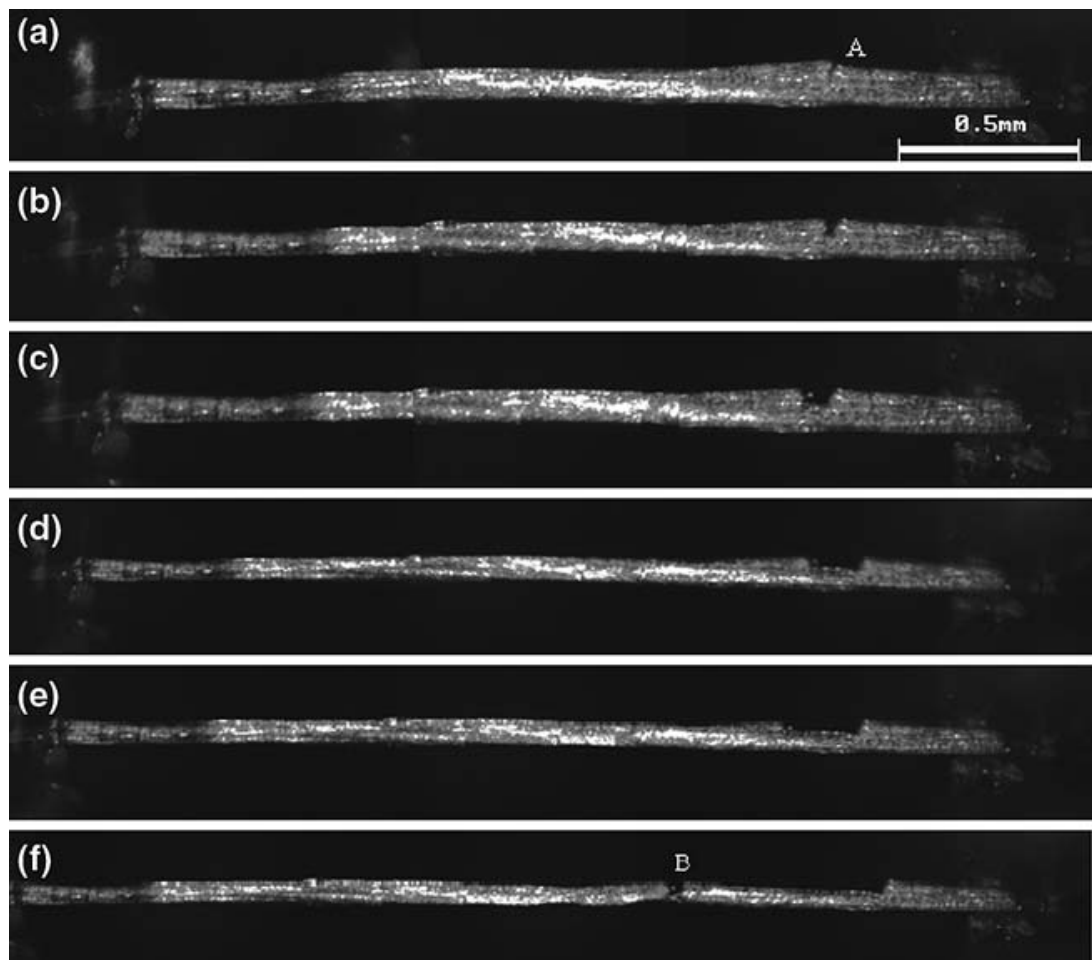

Fig. 10 Non-localized damage in tracheid tensile test. a Local failure is initiated at point A, b-e failure progresses, $\mathbf{f}$ tracheid final failure at point B 
tensile tests show that the hypothesis based on multi-damage and microstructural evolution could be the constitutive mechanism governing the tensile behavior of single wood cells while sliding sticking mechanism with MFA reduction partly contributes to the phenomenon.

\section{Conclusion}

Tensile stress-strain behavior of single wood tracheids is complex, showing load-history dependency. Non-uniformities of MFA and other natural heterogeneities, changing the local properties of the cell wall, affect the tensile behavior of individual wood tracheids. Being unable to visualize the evolution of the ultrastructure of the cell in tension, a micromechanical based model is a useful approach to understand the physical mechanism involved in the complex behavior of wood cells.

By using a simple isotropic damage model, influence of local damage on the longitudinal Young's modulus of the cell wall was calculated and different probabilities of MFA reduction were discussed. The model leads to suggest that the multi-damaging process and microfibrillar evolution are probably the main governing phenomena in tensile behavior of wood cells.

The linear stress-strain domain for a cell with non-uniform MFA is governed by the lowest force level corresponding to the highest MFA. Beyond this level, damage initiates in the matrix of the weakest segment in turn leading to the decrease of the MFA in the damaged zone. Depending on the local MFA as well as the damage stage, the generated irreversible strain could be significant or small. Furthermore, an increase in the applied forces results in the progress of tensile damage in matrix and further MFA reduction that increases the stiffness of the damaged zone. These processes lead to a possibility of multi-damaging phenomenon, damage initiation in the secondweakest segment after evolution in the weakest segment. Multi-damage process, local MFAs reduction and stiffness growth make the cell more homogeneous. This phenomenon may be responsible for the non-yielding segment before failure which is often observed in compression wood tensile behavior.

Acknowledgment The financial support from the Swiss federal office of education and science in the framework of COST E20 and COST E35 is acknowledged with gratitude.

\section{References}

Anagnost SE, Mark RE, Hana RE (2002) Variation of microfibril angle within individual tracheids. Wood Fiber Sci 34(2):337-349

Bergander A, Salmén L (2002) Cell wall properties and their effects on the mechanical properties of fibers. J Mat Sci 37:151-156

Burgert I, Keckes J, Frühmann K, Fratzl P, Tschegg S(2002) A comparison of two techniques for wood fiber isolation-evaluation by tensile tests on single fibers with different microfibril angle. Plant Biol 4:9-12

Cave ID (1968) The anisotropic elasticity of the plant cell wall. Wood Sci Technol 2(4):268-278

Cave ID (1969) The longitudinal young's modulus of Pinus radiata. Wood Sci Technol 3(1): 40-48 
Cho PC, Carleone J, Hsu CM (1972) Elastic constants of layered media. J Composite Mater 6:80-93

Groom L, Mott L, Shaler S (2002a) Mechanical properties of individual southern pine fibers, part I Determination and variability of stress-strain curves with respect to tree height and juvenility. Wood Fiber Sci 34:14-27

Groom L, Shaler S, Mott L (2002b) Mechanical properties of individual southern pine fibers, part III Global relationships between fiber properties and fiber location within an individual tree. Wood Fiber Sci 34:238-250

Harrington JJ (2002) Hierarchical modeling of softwood hygro-elastic properties. University of Canterbury, New Zealand

Harrington JJ, Booker R, Astley RJ (1998) Modeling the elastic properties of softwood. Part I: the cell-wall lamellae. Holz Roh Werkst 56:37-41

Kachanov LM (1986) Introduction to continuum damage mechanics. Martinus-Nijhoff, Dordrecht, Netherlands

Keckes J, Burgert I, Frühmann K, Müller M, Kölln K, Hamilton M, Bughammer M, Roth SV, Stanzle-Tschegg S, Fratzle P(2003) Cell-wall recovery after irreversible deformation of wood. Nat Mater 2:810-814

Kersavage PC (1973) Moisture content effects on tensile properties of individual Douglas-fir latewood tracheids. Wood Fiber Sci 5(2):105-117

Khalili S, Nilsson T, Daniel G (2001) The use of rot fungi for determining the microfibrillar orientation in the $S_{2}$ layer of pine tracheids. Holz Roh Werkst 58:439-447

Mark R (1967) Cell wall mechanics of tracheids. Yale University press, New Haven, Connecticut

Navi P (1988) Three dimensional modeling of wood microstructure for the prediction of fibre elastic properties. Colleque scientifique europèen, Bordeaux, France

Navi P, Sedighi-Gilani M (2004) Modeling the influences of microfibril angles and natural defects on the force-extension behavior of single wood fibers. COST E20 book, pp 57-70

Navi P, Rastogi P, Gresse V, Tolou A (1995) Micromechanics of wood subjected to axial tension. Wood Sci Technol 29:411-429

Navi P, Pittet V, Plummer CJG (2002) Transient moisture effects on wood creep. Wood Sci Technol 36:447-462

Page DH, El-Hosseiny F (1983) The mechanical properties of single wood pulp fibers, Part VI Fibril angle and the shape of stress-strain curve. J Pulp Paper Sci 9:99-100

Perez L, Pittet V, Navi P (2000) Fiber behavior under tensile force, experimentation and modeling. International conference of wood and wood fiber composites, Stuttgart, Germany

Perré P (2001) Wood as a multi-scale porous medium: observation, experiment and modeling. Fist international conference of the European society for wood mechanics, Lausanne, Switzerland

Persson K (2000) Micromechanical modeling of wood and wood fiber properties. Department of mechanics and materials, structural mechanics, LUND University, Sweden

Plummer C, Pittet V, Navi P (2002) Transient moisture effects on wood creep, molecular dynamics. Fist international conference of the European society for wood mechanics, Lausanne, Switzerland

Salmmén L, de Ruvo A (1985) A model for the prediction of fiber elasticity. Wood Fiber Sci 17:336-350

Schniewind AP, Barrett JD (1969) Cell wall model with complete shear restraint. Wood Fiber 1(3):205-214

Sedighi-Gilani M, Sunderland H, Navi P (2005) Microfibril angle non-uniformities within normal and compression wood tracheids. Wood Sci Technol 39:419-430

Sedighi-Gilani M, Sunderland H, Navi P (2006) Within-fiber nonuniformities of microfibril angle. Wood Fiber Sci 38:132-138

Studer T (2005) Transient humidity phenomena in isolated wood fibers: stress-relaxation and fiber twisting. Master of science thesis, Laboratory of constructions materials, EPFL, Switzerland

Tsai SW (1988) Theory of composites design. Think composites, USA

Wang HH, Drummond JG, Reath SM, Hunt K, Watson PA (2001) An improved fibril angle measurement method for wood fibers. Wood Sci Technol 34:493-503 